\title{
Teaching inquiry-driven SEM lab research project on a local environmental geochemistry in the 21st Century

\author{
AFSOON KAZEROUNI
}

Bemidji State University

Presenting Author: afsoonmoatari@yahoo.com

A field-based environmental geochemistry course is created at Bemidji State University for undergraduate geosciences and environmental studies students. This is an inquiry-driven class research project on a local environmental geochemistry issues that is achieved during two-hour laboratory sessions each week. Students are divided into groups that will share the assignments of samples and data collection. Once the data is gathered, it is shared among the entire class so that all students have the same data set. The class works on data presentation, preliminary analysis, and statistics together. Then each student writes their own report separately to (1) improve student understanding of complex environmental systems, specifically targeting lake systems; (2) facilitate student development of professional-level, field- and laboratory-based skills for lake water and sediment analysis; and (3) strengthen student teamwork and communication skills. In this course, students designed and completed a study of water quality in a local kettle lake. The instructor used short "question of the day" exercises, brief lectures, and in-class exercises to familiarize students with analytical and field techniques relevant to the posed problem. At the end of the semester, students presented their work in a public poster session and written report submitted to a local community association. The course was assessed using student work, a preinstruction experience survey, a post-instruction course evaluation, a pre- and post-instruction knowledge test, and a series of interviews with select students. Analysis of the full suite of assessment data suggests that students developed a substantially enhanced understanding of lake systems and the process of eutrophication and perceived that the course improved their analytical and interpersonal skills. However, lowerperforming students and students with weaker backgrounds in geochemistry tended to provide less advanced test responses and showed less ability to transfer knowledge gained in the course to other environmental systems. Generally, students described a strong sense of satisfaction with the original inquiry and community-oriented nature of the course. Therefore, to insure continued high levels of commitment of students in consequent years, we recommend periodically shifting either the field site or the central research question addressed by the class. 